\title{
Crystal structure of dicaesium hexachlorotungstate(IV), $\mathrm{Cs}_{2}\left[\mathrm{WCl}_{6}\right]$
}

\author{
P. Wang ${ }^{\mathrm{I}}$, W. $\mathrm{Xu}^{\mathrm{II}}$ and Y.-Q. Zheng*,II \\ I China Uinversity of Geosciences, Graduate School, Wuchang, Hubei, 430074 P. R. China \\ II Ningbo University, Institute for Solid State Chemistry, Municipal Key Laboratory of Inorganic Materials Chemistry, Ningbo, Zhejiang, 315211 P. R. China
}

Received November 23, 2002, accepted and available on-line January 27, 2003; CSD-No. 409674

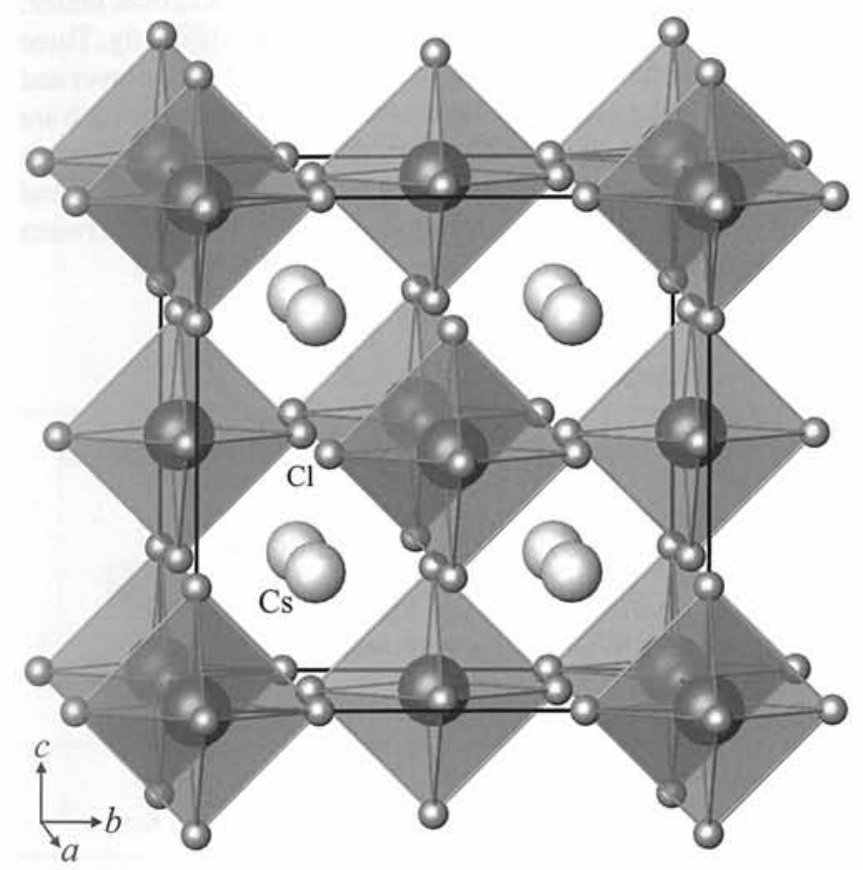

Abstract

$\mathrm{Cl}_{6} \mathrm{Cs}_{2} \mathrm{~W}$, cubic, $F m \overline{3} m$ (No. 225), $a=10.245(1) \AA$, $V=1075.3 \AA^{3}$, $\mathrm{Z}=4, R_{\mathrm{gt}}(F)=0.060, w R_{\mathrm{ref}}\left(F^{2}\right)=0.139, T=293 \mathrm{~K}$.

\section{Source of material}

The reaction of $\mathrm{CsCl}(0.3 \mathrm{~g}, 1.78 \mathrm{mmol}), \mathrm{WCl}_{4}(0.3 \mathrm{~g}, 0.92 \mathrm{mmol})$ and W powder $(0.15 \mathrm{~g}, 0.82 \mathrm{mmol})$ in a sealed silica tube at a temperature gradient of $925 \mathrm{~K} / 915 \mathrm{~K}$ for 1 week afforded a small amount of red octahedral crystals in the lower temperature zone.

\section{Discussion}

The title compound crystallizes with the well-known $\mathrm{K}_{2} \mathrm{PtCl}_{6}$ type structure, consisting of $\mathrm{Cs}^{+}$cations and the $\left[\mathrm{WCl}_{6}\right]^{2-}$ anions. The $\mathrm{W}$ atoms are each octahedrally coordinated by six $\mathrm{Cl}$ atoms, $d(\mathrm{~W}-\mathrm{Cl})=2.369(6) \AA$, and the $\mathrm{Cs}^{+}$cations are each cuboctahedrally surrounded by twelve $\mathrm{Cl}$ atoms, $d(\mathrm{Cs}-\mathrm{Cl})=3.6273(5) \AA$.

Table 1. Data collection and handling.

\begin{tabular}{ll}
\hline Crystal: & red octahedron, size $0.19 \times 0.19 \times 0.20 \mathrm{~mm}$ \\
Wavelength: & Mo $K_{\alpha}$ radiation $(0.71073 \AA)$ \\
$\mu:$ & $188.33 \mathrm{~cm}^{-1}$ \\
Diffractometer, scan mode: & Bruker P4, $\theta / 2 \theta$ \\
$2 \theta_{\text {max }}:$ & $54.8^{\circ}$ \\
$N(h k l)_{\text {measured }}, N(h k l)_{\text {unique }}:$ & 488,90 \\
Criterion for $I_{\text {obs }}, N(h k l)_{\text {gt: }}:$ & $I_{\text {obs }}>2 \sigma\left(I_{\text {obs }}\right), 83$ \\
$N(\text { param })_{\text {refined: }}$ & 7 \\
Program: & SHELXL-97 [1]
\end{tabular}

Acknowledgments. The authors gratefully acknowledge the financial support of National Natural Science Foundation of China (20072022), the Excellent Young Teachers Program of Moe, P. R. China (C982302) and Ningbo Municipal Key Doctor's Funds (0011002).

\section{References}

1. Sheldrick, G. M.: SHELXL-97. Program for the Refinement of Crystal Structures. University of Göttingen, Germany 1997.

Table 2. Atomic coordinates and displacement parameters (in $\AA^{2}$ ).

\begin{tabular}{lllllllllll}
\hline Atom & Site & $x$ & $y$ & $z$ & $U_{11}$ & $U_{22}$ & $U_{33}$ & $U_{12}$ & $U_{13}$ & \\
$\mathrm{~W}$ & $4 a$ & 0 & 0 & 0 & $0.058(1)$ & $U_{11}$ & $U_{11}$ & 0 & 0 \\
$\mathrm{Cs}$ & $8 c$ & $1 / 4$ & $1 / 4$ & $1 / 4$ & $0.054(1)$ & $U_{11}$ & $U_{11}$ & 0 & 0 \\
$\mathrm{Cl}$ & $24 e$ & $-0.2312(6)$ & 0 & 0 & $0.055(3)$ & $0.062(3)$ & $U_{22}$ & 0 & 0 \\
\hline
\end{tabular}

\footnotetext{
* Correspondence author (e-mail: zhengcm@nbu.edu.cn)
} 